\title{
BMJ Open Factors influencing allied health professionals' implementation of upper limb sensory rehabilitation for stroke survivors: a qualitative study to inform knowledge translation
}

\author{
Liana S Cahill (D) ,1,2,3 Leeanne M Carey (D) , ${ }^{1,2}$ Yvonne Mak-Yuen (D) ,,2 \\ Annie McCluskey (D) , ${ }^{4,5}$ Cheryl Neilson (1) , ${ }^{6}$ Denise A O'Connor (D) , 7,8 \\ Natasha A Lannin (1D) 9,10
}

To cite: Cahill LS, Carey LM, Mak-Yuen Y, et al. Factors influencing allied health professionals' implementation of upper limb sensory rehabilitation for stroke survivors: a qualitative study to inform knowledge translation. BMJ Open 2021;11:e042879. doi:10.1136/ bmjopen-2020-042879

- Prepublication history and additional material for this paper is available online. To view these files, please visit the journal online (http://dx.doi.org/10. 1136/bmjopen-2020-042879).

Received 17 July 2020 Revised 05 January 2021 Accepted 27 January 2021
Check for updates

(C) Author(s) (or their employer(s)) 2021. Re-use permitted under CC BY-NC. No commercial re-use. See rights and permissions. Published by BMJ.

For numbered affiliations see end of article.

Correspondence to

Liana S Cahill;

liana.cahill@acu.edu.au

\section{ABSTRACT}

Objectives Somatosensory loss is common after stroke with one-in-two individuals affected. Although clinical practice guidelines recommend providing somatosensory rehabilitation, this impairment often remains unassessed and untreated. To address the gap between guideline recommendations and clinical practice, this study sought to understand the factors influencing delivery of evidencebased upper limb sensory rehabilitation after stroke. Design Qualitative study involving focus groups and interviews. Data analysis used an inductive approach (thematic analysis) and deductive analysis using implementation theory (the Theoretical Domains Framework and Normalisation Process Theory). Setting Eight healthcare organisations in metropolitan and regional areas of Victoria and New South Wales, Australia.

Participants Eighty-seven rehabilitation therapists (79\% occupational therapists and $21 \%$ physiotherapists) were purposively sampled and participated in a knowledge translation study with staggered recruitment from 2014 to 2018.

Results Three types of factors influenced therapists' delivery of upper limb somatosensory rehabilitation: individual ('The uncertain, unskilled therapist'), patient ('Patient understanding and priorities') and organisational ('System pressures and resources'). Deductive analysis using implementation theory identified key determinants of practice change, such as opportunities to consolidate new skills, the anticipated benefits of upskilling as a therapy team and the work anticipated by therapists to incorporate a new somatosensory rehabilitation approach.

Conclusions Occupational therapists and physiotherapists hold valuable insights towards practice change in somatosensory rehabilitation from the 'frontline'. Therapists experience barriers to change including a lack of knowledge and skills, lack of resources and organisational pressures. Facilitators for change were identified, including social support and therapists' perceived legitimacy in using new somatosensory rehabilitation approaches. Results will inform the design of a tailored implementation strategy to increase the
Strengths and limitations of this study

- This study used a qualitative design with inductive and deductive data analysis guided by the Theoretical Domains Framework and Normalisation Process Theory to increase credibility of findings.

- A strength of this study is that it sought input from eight different health organisations and included a relatively large sample of therapists $(n=87)$ with experience in stroke rehabilitation.

- Three independent researchers were involved in data analysis to increase validity.

- Focus groups included therapists with different levels of experience and seniority, which may have introduced a power differential during discussion and potential for response bias.

- The perspectives of stroke survivors and health organisation managers were not included in this study.

use of evidence-based somatosensory rehabilitation in Australia.

Trial registration number Australian New Zealand Clinical Trials Registry (ACTRN12615000933550).

\section{BACKGROUND}

Somatosensation has been considered the most complex of the human senses ${ }^{1}$ and includes tactile discrimination, joint position sense, haptic object recognition and pain. Half of all stroke survivors experience somatosensory $\operatorname{loss}^{2-5}$ yet treatment for this impairment has been historically overlooked. ${ }^{67}$ Research reveals a persistent evidence-practice gap in the area of somatosensory rehabilitation..$^{8-10}$ Somatosensory rehabilitation includes assessment of somatosensory loss and treatment of somatosensory modalities ${ }^{11}$ by occupational therapists and physiotherapists. Their accurate detection of somatosensory deficits, 
such as impaired touch, proprioception or haptic object recognition, gives stroke survivors an opportunity for treatment.

Standardised assessments are underused by occupational therapists and physiotherapists, with informal measures being more common. ${ }^{8}$ Typical treatment for somatosensory loss focusses on compensation (such as providing education to avoid limb injury), with a lack of use of evidence-based treatments aimed at regaining somatosensory function. ${ }^{8}$ These practices may discount stroke survivors' perceptions of somatosensory loss as being 'significant', 'concerning', and having a negative impact on daily life and promote a perception that the impairment cannot be treated. ${ }^{12-14}$

Following the publication of a Cochrane review, ${ }^{15}$ evidence for somatosensory rehabilitation has increased. ${ }^{16}$ A more recent systematic review found that discrimination retraining programmes may improve upper limb somatosensory impairment after stroke. ${ }^{11}$ SENSe therapy is a discrimination retraining programme for upper limb somatosensory loss and uses principles such as attentive exploration and calibration to remediate somatosensory function. ${ }^{16}$ Stroke clinical guidelines recommend standardised assessment and sensory-specific treatment for somatosensory loss. ${ }^{17-19}$ However, clinical audits suggest that these recommendations are not widely implemented. ${ }^{9}$

Factors contributing to the underuse of somatosensory assessment and treatment were explored in one Australian study. ${ }^{20}$ Occupational therapists and physiotherapists in this study $(\mathrm{n}=172)$ based their assessment and treatment choices on prior knowledge and clinical experience rather than research, as well as organisational factors such as time available and patient length of stay. ${ }^{20}$ Patient factors also influenced practice; somatosensory assessments were often not completed if a stroke survivor did not raise loss of sensation as a concern, or therapists believed that a patient could not participate in the assessment. These findings are consistent with stroke rehabilitation more broadly, where use of evidence in practice is influenced by a lack of time, knowledge and staffing issues, and patient factors such as prioritisation and safety. ${ }^{21}$ There is a need for further research into factors that influence clinical decision-making for stroke survivors with somatosensory loss. ${ }^{82}$

Doyle and Bennett ${ }^{23}$ investigated clinical behaviour in somatosensory rehabilitation in a survey of occupational therapists prior to delivering a workshop based on the Theory of Planned Behaviour. Therapists reported a lack of knowledge and skills to deliver somatosensory rehabilitation, and a lack of resources and time to locate evidence and use unfamiliar assessments and treatments. The sample for this study was small $(\mathrm{n}=19)$, and responses were limited to a self-report questionnaire. A more in-depth study is required, involving perspectives from both occupational therapists and physiotherapists who provide somatosensory rehabilitation to stroke survivors.

The aim of our study was to understand the barriers and enablers faced by occupational therapists and physiotherapists in the implementation of somatosensory assessments and interventions for stroke survivors, to provide an explanation of underlying mechanisms that enhance or inhibit such implementation. As this study sought to explore barriers, enablers and any other factors influencing implementation of somatosensory guidelines in practice, the use of implementation theory was warranted.

Implementation science is a field of study dedicated to methods for increasing use of research in practice ${ }^{24}$ and the use of theory is central to the field..$^{25}$ Theory helps provide a framework for investigating influences on behaviour, and a process for guiding behaviour change interventions. ${ }^{26}$ Theoretical approaches in implementation science are often interdisciplinary, drawing on fields of psychology, sociology and economics. ${ }^{27}$ The theories applied in this study were the Theoretical Domains Framework (TDF) ${ }^{28}$ and Normalisation Process Theory (NPT) ${ }^{29}$ Use of multiple theories, common in implementation research, provided an opportunity to view barriers and enablers from different perspectives and avoid a 'conceptual straight-jacket' ${ }^{30}$ The TDF, based on psychological theory, offers a comprehensive, synthesised lens to explore individual motivators and capabilities for change, and social and environmental influences on behaviour. ${ }^{31}$ NPT provides an alternative theoretical lens and is a sociological theory that considers work required by individuals and groups to embed, or normalise, a new practice.

\section{PROCEDURE}

This qualitative study presents data from focus groups and interviews conducted with occupational therapists and physiotherapists, to enable the development of a tailored implementation strategy. A primary goal of the implementation strategy was to improve the routine use of somatosensory assessments and interventions after stroke. $^{32}$

\section{Design}

We used a descriptive qualitative design to explore determinants of practice ${ }^{33}$ and help explain and describe complex processes and behaviours. Data were collected at eight healthcare organisations using preimplementation questionnaires and focus groups of 1 hour duration. Two members of the research team (LSC and YM-Y) attended focus groups; LSC facilitated focus groups and YM-Y took notes about group interactions and non-verbal communication. If therapists were unable to attend the focus group, separate interviews (20-30 min duration) were held face-to-face or via telephone by LSC. Content of focus groups was not discussed in individual interviews. Focus group and interview questions were the same (online supplemental appendix 1), were open ended and were informed by the TDF. ${ }^{28}$ 


\section{Participants}

Participating health organisations were recruited to the study by LMC through telephone, direct contact and face-to-face meetings with managers. All organisations were in Australia; seven in Victoria and one in New South Wales. Participants were graduate occupational therapists and physiotherapists working with stroke survivors in participating healthcare organisations. There was no minimum clinical experience level required for eligibility to participate. Participant recruitment occurred via an information session presented by LSC and YM-Y held at participating organisations where purposive sampling was used. All participants provided written informed consent to participate in the study.

\section{Research team reflexivity}

LSC acted as the facilitator for focus groups and interviews and was the primary coding researcher. YM-Y was the notetaker for focus groups. LSC is a neurological occupational therapist with a Masters of Public Health and a university lecturer completing a doctorate on knowledge translation in somatosensory rehabilitation. LSC completed workshop training on focus group facilitation prior to leading the focus groups. $\mathrm{YM}-\mathrm{Y}$ is an experienced neurological occupational therapist, completing her doctorate on standardised assessment in somatosensory rehabilitation. LSC had previously worked with some participants at four sites but not at the time of the focus groups and interviews; YM-Y had not worked with any participants previously. Both LSC and YM-Y have experience assessing and treating somatosensory loss in stroke survivors, and have published and presented on somatosensation in stroke at conferences. This interest in somatosensory rehabilitation may have been known to participants and be a potential source of bias.

NAL and AM were coding researchers in this study. Both are experienced neurological occupational therapists and senior researchers, who have been involved in the development of stroke clinical guidelines and stroke implementation studies. NAL and AM were not involved in data collection, and remained blind to the source of quotes they were coding.

\section{Patient and public involvement}

Patients and/or the public were not directly involved in the design, recruitment or implementation of this qualitative study. Consumer representatives are members of the broader SENSe Implement Steering Committee and provided input to design. Regular reviews by consumers of the SENSe study documents (policies and reports) are undertaken.

\section{Data analysis}

Focus groups and interviews were audio recorded with participant consent and transcribed verbatim by authors (LSC and YM-Y). Field notes were taken during and after each focus group and interview. All organisations and participants were given a unique identifier. A twostaged approach to analysis was used to inductively identify key themes (stage 1), then data were deductively coded against the TDF and NPT (stage 2) using a theoryinformed approach. Two members of the research team conducted the analysis in each phase. Any discrepancies were resolved through discussion and review of the original transcripts.

\section{Stage 1: thematic analysis}

First an inductive approach was applied using thematic analysis to identify and interpret key themes. ${ }^{34} 35$ Two researchers (LSC and AM) open coded a sample of transcripts (20\%, three transcripts) line-by-line, then met regularly to develop and revise the coding framework. LSC analysed remaining transcripts with ongoing consultation with coauthors. An audit trail of discussions and decisions was kept, leading to resultant codes, categories and ultimate themes.

\section{Stage 2: analysis using the TDF and NPT Theoretical domains framework}

A deductive analysis approach was then taken using the TDF. ${ }^{28}$ LSC and NAL separately coded a sample of transcripts (20\%, three transcripts) to relevant domains of the TDF and met regularly to compare and discuss coding decisions. LSC analysed the remaining transcripts, which were collated into domain codes, discussed and revised through an iterative process with NAL. See online supplemental appendix 2 for the TDF codebook.

\section{Normalisation process theory}

A complementary deductive analysis occurred using NPT. ${ }^{29}$ Coding to NPT provided insights into how teams of therapists conceptualised somatosensory rehabilitation. It is acknowledged NPT constructs need to be given their own working definition for individual settings ${ }^{36}$ to make NPT 'at home' in the context of the study. ${ }^{37}$ This process was completed through iterative discussion between LSC and AM (see online supplemental appendix 3 for NPT codebook). LSC and AM separately coded a sample of transcripts (20\%, three transcripts) to categories and constructs of the NPT, followed by discussion. LSC analysed the remaining transcripts, resultant category and construct codings were reviewed, discussed and refined in meetings with AM.

The coding frameworks and domains, categories and constructs in the second and third stages of analysis were reviewed for agreement by LSC, NAL and AM.

\section{FINDINGS}

Eighty-seven occupational therapists and physiotherapists participated in focus groups and interviews across eight healthcare organisations. Six organisations were public healthcare organisations (government funded) and 


\begin{tabular}{lc}
$\begin{array}{ll}\text { Table } 1 \text { Characteristics of participants } \\
\text { Characteristic }\end{array}$ & $\mathbf{n = 8 7}$ \\
\hline $\begin{array}{l}\text { Sex, number female (\%) } \\
\text { Discipline, number (\%) }\end{array}$ & \\
$\begin{array}{l}\text { Occupational therapist } \\
\text { Physiotherapist }\end{array}$ & $69(79)$ \\
$\begin{array}{l}\text { Highest education level, number (\%) } \\
\quad \text { Bachelor degree }\end{array}$ & $18(21)$ \\
$\quad$ Coursework masters & $72(83)$ \\
$\quad$ Research masters & $6(9)$ \\
$\quad$ Not specified & $1(1)$ \\
$\begin{array}{l}\text { Years of clinical experience (years), } \\
\text { mean (SD) }\end{array}$ & $10.6(2.1)$ \\
$\begin{array}{l}\text { Years of experience working with stroke } \\
\text { survivors (years), mean (SD) }\end{array}$ & $7.9(3.5)$ \\
\end{tabular}

two sites were private (privately funded). Tables 1 and 2 outline participant and site characteristics.

Table 3 provides an overview of themes and codes in different analysis stages.

\section{Phase 1: thematic analysis}

Three main themes or factors, and associated subthemes, were found to influence therapists' delivery of upper limb somatosensory rehabilitation: the uncertain unskilled therapist, patient understanding and priorities, and system pressures and resources.

Theme one: the uncertain unskilled therapist

A key finding was a self-identified lack of knowledge, skill and confidence to deliver somatosensory rehabilitation. Therapists expressed negative emotions related to

Table 2 Overview of organisations and participants in focus groups and interviews (total participants $n=87$ )

\begin{tabular}{|c|c|c|c|}
\hline \multirow[b]{2}{*}{ Organisation } & \multirow[b]{2}{*}{$\begin{array}{l}\text { Type of health } \\
\text { service and } \\
\text { location* }^{*}\end{array}$} & \multirow{2}{*}{$\begin{array}{l}\text { Focus } \\
\text { groups } \\
\text { Number of } \\
\text { participants } \\
\text { (no. of focus } \\
\text { groups) }\end{array}$} & \multirow{2}{*}{$\begin{array}{l}\text { Interviews } \\
\begin{array}{l}\text { Number of } \\
\text { participants } \\
\text { (no. of } \\
\text { interviews) }\end{array}\end{array}$} \\
\hline & & & \\
\hline 1 & Tertiary, metropolitan & $10(1)$ & $1(1)$ \\
\hline 2 & Tertiary, metropolitan & $9(1)$ & $0(0)$ \\
\hline 3 & Tertiary, regional & $15(2 \dagger)$ & $0(0)$ \\
\hline 4 & Tertiary, metropolitan & $13(2 \ddagger)$ & $0(0)$ \\
\hline 5 & Tertiary, metropolitan & $6(1)$ & $1(1)$ \\
\hline 6 & Tertiary, regional & $6(1)$ & $1(1)$ \\
\hline 7 & Tertiary, metropolitan & $12(1)$ & $0(0)$ \\
\hline 8 & Tertiary, metropolitan & $13(2 \S)$ & $0(0)$ \\
\hline
\end{tabular}

*All organisations have dedicated rehabilitation services, engage in research and teaching and have affiliations with a university.

†First focus group $=12$, second focus group $=3$.

$\neq$ First focus group $=10$, second focus group $=3$.

$\S$ First focus group $=6$, second focus group $=7$. these experiences and were concerned about using new somatosensory approaches in the 'right' way. Therapists acknowledged they often had little awareness of standardised assessments:

It was realising there's...objective assessments... and not knowing any of them! So that's a bit scary (P4, Physiotherapist, Site 1, focus group)

Uncertainty about using assessment information to address sensory loss was also acknowledged:

I find that I tend to assess, but then I don't know what to do with that information. (P1, Occupational therapist, Site 5, focus group)

Therapists were aware of their limitations when required to deliver somatosensory rehabilitation. They experienced various emotions including 'guilt' and 'frustration':

I feel a little bit guilty... about what I have been doing in the past. This...shows me how much more I could have been doing (P3, Occupational Therapist, Site 5, focus group)

Therapists expressed a lack of confidence related to somatosensory rehabilitation, which led them to deprioritise this area of practice and focus on others:

I find that it isn't a priority for me to assess... as I don't feel confident with it and it kind of gets pushed to the left over time in the session (P1, Occupational therapist, Site 2, focus group)

Subtheme: the importance of getting it right

Therapists felt a weight of responsibility to change their practice, and use new knowledge and skills appropriately to benefit patients:

I think there's also that little bit of hesitation of something new.... am I going to do it right? ( $P 5$, Occupational therapist, Site 8, focus group 1)

Lack of skill consolidation after upskilling in evidencebased sensory rehabilitation was a concern to some therapists. Without consistency of practice some therapists worried they might not be ready when the need for their somatosensory skills arose:

I also feel a little bit nervous...with doing this amazing training and there will be no-one to use it on for 6 months... when I finally get to that client, will I be ready? (P4, Occupational therapist, Site 8, focus group 2)

Theme two: the patient's understanding and priorities

This theme encompassed therapists' perceptions of patient understanding of sensation, the goals set in rehabilitation and the therapist's role in helping patients understand sensation. Therapists wanted to be guided by patients and set patient-centred goals, but highlighted a lack of understanding about sensation by some stroke 
Table 3 Overview of themes and prominent codes

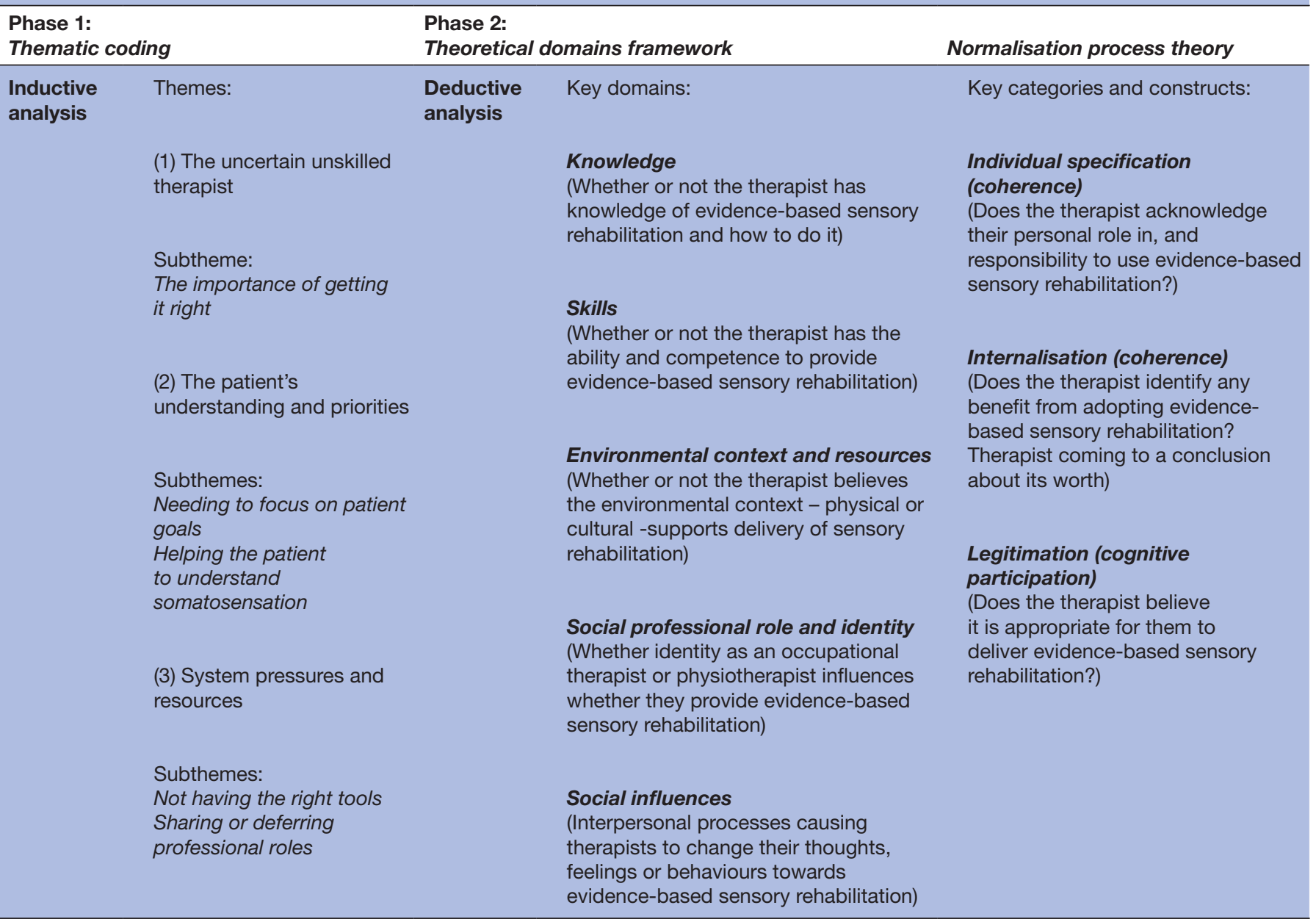

survivors. Sensation was seen as a more abstract concept to patients when contrasted with motor deficits which were more easily described and understood:

There's often a confusion between motor and sensation...sometimes they'll say 'My muscles need to be stronger' but when you test it's very obvious that it's not actually a motor issue, it's...more of a sensory impairment (P3, Occupational therapist, Site 6, focus group)

Patient priorities were often perceived to be in areas other than somatosensory rehabilitation, particularly for inpatients:

From an inpatient perspective it's [sensation] quite often... not the client's priority (P3, Occupational therapist, Site 2, focus group)

\section{Subtheme: needing to focus on patient goals}

Goal setting, as a tenet of stroke rehabilitation, was proposed to guide therapists in practice. However, not all patients wanted to set 'sensory-goals' and this perception impacted on therapists' clinical decision-making to conduct somatosensory assessments and provide subsequent treatment:

You can't assess it (sensation) and treat it if it's not their goal. It has to be goal driven (P1,Occupational therapist, Site 6, focus group)

\section{Subtheme: helping patients to understand somatosensation}

When patients lacked an understanding of sensation, many therapists believed it was part of their professional role to increase patients' knowledge about the impact of somatosensory loss on upper limb function. Therapists at separate sites independently described the importance of this role for giving patients a 'lightbulb' moment:

It's not until you take time and assess and explain how that [sensation] would be affecting the motor problems, and it's almost like a light bulb for people...they haven't had the words to articulate it (P12, Occupational therapist, Site 7, focus group)

Others mentioned that it suited therapists that patients often didn't understand sensation and prioritise this 
because they did not know how to deliver somatosensory rehabilitation anyway:

I do find myself wondering whether it's a bit of a chicken and the egg situation...it kind of suits us that sensory stuff is down the bottom but I'm not sure how that goes. Have we articulated that to the patients, to try to help them to understand, or is that an accurate reflection of the patient's experience? $(P 7$, Occupational therapist, Site 8, focus group)

\section{Theme three: system pressures and resources}

This theme includes pressures experienced by therapists in their organisations, the lack of resources to deliver somatosensory rehabilitation and sharing work responsibilities within a rehabilitation team. Therapists across all sites described organisational factors that created competing demands and reduced opportunities to provide somatosensory rehabilitation. There was pressure, particularly on inpatient therapists, to facilitate discharge for patients and this was perceived as highly valued by their organisation. This expectation often came at the expense of providing upper limb somatosensory rehabilitation:

To facilitate someone to go home, or leaving the hospital is more highly valued [than somatosensory rehabilitation] (P2, Occupational therapist, Site 7, focus group)

Therapists working in the community, rather than inpatient settings, were less affected by hospital discharge pressures but still experienced competing demands related to their own, rather than organisational expectations:

I find I can't really spend an hour just doing sensation...maybe half an hour doing sensation and then all the return to work and everything else that's going on, so... being able to dedicate pure session for upper limb retraining is hard (P8, Occupational therapist, Site 1, focus group)

\section{Subtheme: not having the right tools}

Lack of appropriate equipment to assess and treat somatosensory deficits was a common barrier for therapists. Disorganised equipment and tools were observed by some as a representation of time and effort placed on somatosensory rehabilitation to date:

We have bits and pieces, scraps of stuff that we kind of throw together and we haven't got any formal, really good quality assessments or treatments, you know just hobbled together stuff...so it kind of reflects the importance or...how much time we put into it $(P 7$, Occupational therapist, Site 8 focus group 2)

Therapists, however, anticipated that having the right equipment would improve their practice and skill development, and improve their confidence in delivering somatosensory rehabilitation:
If you have the proper equipment, we will be more confident to use it and we'll look more professional too (P6, Occupational therapist, Site 7, focus group)

\section{Subtheme: sharing or deferring professional roles}

Occupational therapists and physiotherapists spoke of overlapping professional responsibility in the delivery of somatosensory rehabilitation, and in some situations, sharing the workload.

More often, responsibility for upper limb somatosensory rehabilitation was assumed by the occupational therapist. This role expectation was often related to physiotherapists' workload and the need to delegate to focus on other rehabilitation areas:

I'll be the first to admit if I've got an OT working with my client at the same time, then I won't prioritise upper limb sensory (P6, Physiotherapist, Site 6, focus group)

\section{Phase 2: analysis using implementation theory}

An overview of coding to domains and categories of the $\mathrm{TDF}^{28}$ and $\mathrm{NPT}^{29}$ is provided in online supplemental appendix 4 .

\section{Analysis using the TDF}

The domains coded most frequently were Knowledge, Skills, Environmental context and resources, Social professional role and identity, and Social influences.

\section{Knowledge}

In alignment with thematic coding, lack of knowledge about somatosensory rehabilitation was frequently coded as a barrier to evidence-based practice. Procedural knowledge, a construct of the Knowledge domain, prompted coding of sources of knowledge. Therapists felt that their university education had often left them unprepared to provide somatosensory rehabilitation:

When I went through university as well...I don't think it was an area that I believe was well taught at that time...I didn't feel like I had a good grounding to even run with (P4, Occupational therapist, Site 6, focus group)

Opportunities for development of somatosensory knowledge in the workplace were also scarce for some therapists, as were opportunities to acquire skills by observing or asking colleagues:

... it's (sensory rehabilitation) not something that you can learn off a colleague ... This is not an area where I can ask one of my more experienced colleagues about, it's not something that they would necessarily know (P3, Occupational therapist, Site 8, focus group 2)

The TDF Knowledge domain also highlighted what therapists knew about the impact of somatosensory loss on patients, and gaps in therapist knowledge:

... sometimes it's hard for us to understand the impact of sensory loss. Motor loss you can see the impact... 
but if they have functional upper limb but sensation is the main issue, I don't think we are as good at realising how much of an impact that could have (P1, Occupational therapist, Site 5, focus group)

\section{Skills}

Coding to the Skills domain of the TDF highlighted a perceived skill gap and barrier to evidence-based practice. The ability to develop and consolidate skills through exposure to appropriate patients was seen as an enabler for sustaining skill levels:

.... and to consolidate early so then it becomes second nature rather than lose all the knowledge that we've learnt (P3, Occupational therapist, Site 1, focus group)

Coding to this domain also highlighted the need for specialised skills when working with stroke survivors with common poststroke deficits such as aphasia or cognitive impairment who needed somatosensory rehabilitation:

Clients that do have communication impairments is the other one... how do I get them to talk this out?... in the past we've done some comparisons with things but if they don't have the language, I really don't know what to do (P6, Occupational therapist, Site 8, focus group 2)

\section{Environmental context and resources}

Within this TDF domain, the constructs of environmental stressors, resources and person versus environment interactions were most relevant. Environmental stressors were recognised most by inpatient therapists and corresponded with findings in thematic coding (see 'System pressures and resources'). Resources referred to equipment and physical spaces that were needed to deliver somatosensory rehabilitation, including quiet rooms to facilitate sustained attention on assessments and therapy:

To get to a private space or a quiet space to do the assessment or to have the equipment somewhere easy in a quiet space, that might be a physical barrier ( $P 3$, Physiotherapist, Site 3, focus group 2)

Theoretically, the workplace provided a supportive culture for evidence-based practice, but practically, implementation was often left up to individual therapists:

Quite often it feels like it's up to individual therapists to - which makes sense - to bring on change...but in order to do that ....requires a lot of ...energy and effort. And so the organisation embraces it but not necessarily enables it to happen easily (P3, Occupational therapist, Site 6, focus group)

\section{Social professional role and identity}

Therapists commented on two predominant areas within this TDF domain: their own professional role and identity, and their organisation's identity or 'brand' and how these factors influenced their perspective and practice.
Physiotherapists mentioned that they would often defer upper limb sensory rehabilitation to occupational therapists (as per thematic coding, System pressures and resources, subtheme 'Sharing and deferring professional roles'). Occupational therapists communicated that although upper limb sensory rehabilitation was a part of their job and assumed expertise, it was not a role they were always comfortable with:

In terms of the other disciplines, they look to us (OT) as an expert in this area, and there's a very uncomfortable feeling (P7, Occupational therapist, Site 8, focus group 2)

Organisational identity was also mentioned as an enabler by therapists at organisations which aspired to high-quality healthcare, for example, through involvement in research and delivery of evidence-based practice. Therapists felt that this quality brand aligned with their own desire to provide evidence-based stroke rehabilitation and justified their efforts to implement somatosensory rehabilitation:

We've got a very strong commitment to...using evidence-based practice, and keeping abreast of new research and new techniques that are coming out (P1, Physiotherapist, Site 1, interview)

\section{Social influences}

Interpersonal processes had an impact on therapists' delivery of somatosensory rehabilitation. This influence was exerted by work colleagues, either peers or managers or patients. Colleagues supported practice change. The intended team training was anticipated to be beneficial, in contrast to individuals attending a professional development training session and trying to effect change:

It will be really helpful having so many therapists who actually know how to do it [sensory rehabilitation]... we can spur each other on and to get each other to do it (P9, Occupational therapist, Site 7, focus group)

Patients also influenced whether somatosensory rehabilitation was provided or not. Community-based therapists expressed that a precedent could be set when therapy was provided during inpatient rehabilitation. However, if somatosensory impairments were not identified and/or treated there, patients may not want to focus on sensory rehabilitation:

What they've [patient] been focused on as an inpatient often comes with them... 'I worked on this while I was in hospital, I want to keep working on it'...so introducing those new things [sensory rehabilitation] can also be a challenge (P10, Occupational therapist, Site 1, focus group)

Therapists found some patients were well-informed about treatment options and wanted to pursue evidencebased rehabilitation: 
I'm finding that some patients are very savvy and have read up a lot about things and they will actually say 'Are you doing this treatment technique?'...I've had a couple of people who...have asked for some of the sensory things (P8, Occupational therapist, Site 2, focus group)

\section{Analysis using NPT}

Constructs most frequently used were coherence, including individual specification and internalisation, and cognitive participation, specifically the construct of legitimation. Coherence refers to work done to make sense of using a new practice, whereas cognitive participation refers to relational work done to build enrolment and engagement in a new practice. ${ }^{29}$

\section{Coherence: individual specification}

Individual specification in this study related to therapists' understanding of their personal roles and responsibilities related to evidence-based somatosensory rehabilitation. Therapists were aware that they needed to move forward from previous practice patterns to incorporate something new:

Just breaking what's old habits and changing practice and not defaulting to what's easy when we are feeling pressured and busy and tired.... (P10, Occupational therapist, Site 1, focus group)

Therapists also recognised their role in learning new skills related to equipment use and also providing therapy that required a high level of mastery of therapy techniques:

More just that translating that training [in sensory rehabilitation] to then mastering that skill and remembering it (P1, Occupational therapist, Site 6, interview)

\section{Coherence: internalisation}

Internalisation in this study referred to therapists' understanding of the value and benefit of using new evidencebased somatosensory rehabilitation approaches, and coming to a conclusion about the practice. ${ }^{38}$ Most therapists held positive views about the effectiveness of the new approach and how it would add to their repertoire of skills:

The impression that the treatment approach works so that is what I'm basing my enthusiasm on, that it is actually going to improve people's sensation and translate into their function (P5, Occupational therapist, Site 2, focus group)

Therapists at some sites observed colleagues using new somatosensory rehabilitation approaches, which contributed to conclusions drawn about the approach:

I can see the difference in the results as well that people who get SENSe training get (P8, Occupational therapist, Site 7, focus group)

\section{Cognitive participation: legitimation}

Legitimation in this study referred to therapists' beliefs about whether or not it was appropriate for them to be involved with the new evidence-based sensory rehabilitation approach, in their particular context. Some therapists believed that the evidence base for somatosensory rehabilitation legitimised their future use of it, and helped support the anticipated time required to change practice:

Because there's evidence behind this program already...there's a bit more weight to it in terms of when you are selling it to other health professionals or to our clients and their families in terms of how much time is needed (P2, Occupational therapist, Site 5, focus group)

Therapists from an inpatient setting wondered how their patients would participate in the therapy. Some believed that this area of practice was more suitable for use by their community-based colleagues:

I'm not sure how well received the treatment would be with all of our patients (P1, Occupational therapist, Site 5, focus group)

Some therapists felt that somatosensory rehabilitation was considered to be an assumed skill by managers, which justified their involvement in, and use of the new rehabilitation approach:

I don't necessarily think we would have...barriers put up by our direct managers....I think to a degree they'd already expect us to be doing this as part of our jobs (P7, Occupational therapist, Site 1, focus group)

The need for extensive one-to-one therapy as part of this new approach, which required 'hands-on' intervention, was felt to be at odds with current practice at one site, and a potential barrier to practice change, with therapists stating that:

There is a move for...more self-directed [therapy]... the patient taking ownership of their problem and working on that themselves, rather than you sitting down one-on-one (P10, Physiotherapist, Site 3, focus group 1)

Finally, therapists talked about the importance of goaldirected rehabilitation and felt that SENSe therapy was aligned with this principle:

It's a goal-based service...the client has a lot of input into their...rehabilitation... by having really specific goals. So it's helpful that SENSe is very goal orientated as well (P9, Occupational therapist, Site 7, focus group)

\section{DISCUSSION}

Findings suggest three main factors influencing delivery of upper limb somatosensory rehabilitation by therapists: individual therapist factors ('The uncertain unskilled 
therapist'), patient factors ('The patient's understanding and priorities') and organisational factors ('System pressures and resources'). This study used a multiphased approach for analysis, including both psychological and sociological implementation theories. Initial inductive analysis allowed a data-driven exploratory approach before use of deductive analysis mapped data to predetermined theoretical constructs. Implementation theory highlighted key determinants of practice, such as opportunities for practice to consolidate new skills (TDF domain 'Skills'), the anticipated benefits of upskilling as a therapy team (TDF domain 'Social influence'), and the tendency of physiotherapists to defer to occupational therapists for upper limb somatosensory rehabilitation (TDF domain 'Social professional role and identity'). NPT highlighted the work anticipated and required by therapists, including the time and effort, to incorporate a new approach into practice and learn practical aspects of equipment use. This phased approach to analysis has previously been used in implementation research ${ }^{39}$ and avoids theoretical 'blinders' resulting from a single method. ${ }^{25}$

Given the known evidence-practice gaps in somatosensory rehabilitation, ${ }^{840}$ it is unsurprising that knowledge and skill barriers were prominent, consistent with previous studies. ${ }^{20}{ }^{41}$ Patient factors were rightfully important to therapists. Therapists wanted to be directed by patients about their stroke rehabilitation goals, but acknowledged that sensation was a poorly understood, abstract concept for many patients. For that reason, patients often did not raise sensation as an issue nor set 'sensory goals'. A cycle of patient non-inquiry and therapist non-delivery of somatosensory rehabilitation was suggested, which may be important to address during implementation. Interestingly, therapists sometimes delineated between sensory goals that were impairment based and 'functional goals' which were not, without noting the association between somatosensory capacities and occupational performance. ${ }^{42} 43$

The role of physiotherapists in somatosensory rehabilitation was also explored through this research. Although the proportion of physiotherapists in the sample was relatively small (21\%), one theme that was evident across several sites was that occupational therapists assumed the primary role for upper limb somatosensory rehabilitation, with physiotherapists focused on other areas such as mobility retraining. This finding has potential implications for involving physiotherapists in somatosensory rehabilitation and tailored strategies for behaviour change, such as training, persuasion and modelling, are likely required. ${ }^{44}$

Organisational pressures were felt strongly by therapists. Inpatient therapists were particularly influenced by discharge pressures. This pressure often compromised their ability to provide upper limb rehabilitation. Some therapists suggested that it might not be feasible for them to deliver somatosensory rehabilitation in their inpatient setting. This finding is similar to other studies where discharge pressure influenced provision of rehabilitation. ${ }^{45} 46$ Social influences from colleagues and patients were identified as both enabling and hindering factors for change. Therapists held positive views about anticipated implementation efforts that would be directed towards them as a group rather than individuals. They perceived benefits of upskilling the whole therapy team and working together to use a new therapy approach.

Implementation theory helped to further elucidate perceptions towards changing practice and factors influencing translation. Mapping to domains of the TDF and NPT revealed common data points for triangulation, a layered understanding of themes, and new factors influencing the implementation of evidence-based somatosensory rehabilitation not apparent during initial coding. An example of intersection between theoretical approaches used in this study was between the NPT category of 'Coherence: internalisation' and the TDF domain of 'Beliefs about consequences'. Therapists' positive views towards the new somatosensory intervention and its effectiveness were mapped to both of these components. Similarly, the TDF domain of 'Social professional role and identity' was found to align with the NPT category of 'Cognitive participation: legitimation' in therapists' belief the intervention may be more suitable for community-based therapists.

Two other studies have used both the TDF and NPT to explore implementation issues ${ }^{474}$ and multiple studies have applied more than one implementation theory. ${ }^{49}$ This study mapped data to implementation theory, improving our understanding of factors which influence practice change, such as professional identity and work anticipated by therapists to embed a new therapy. The findings in this study will be used to further tailor implementation strategies in the SENSe Implement knowledge translation study. ${ }^{32}$ Improved understanding of key determinants of practice change suggest the value of individual consolidation of skills in somatosensory rehabilitation, upskilling as a therapy team, and organisational support for resources and change.

\section{Strengths and limitations}

There were several strengths of the study design and methods. First, the use of multiphased analysis and implementation theory can heighten the sensitivity of researchers to interpretations that may not occur using inductive analysis alone. ${ }^{36}$ Second, the number of health professionals $(n=87)$ across eight different health organisations provided a relatively large sample of stroke rehabilitation therapists. Therapists unable to attend initial focus groups were followed up in individual interviews, allowing part-time therapists, and those in senior roles with family/carer responsibilities to participate. Their perspectives were valued. Participating health organisations were purposively selected by the research team. A limitation may have been that management personnel within these organisations influenced which therapists participated in the study. These factors may have introduced sampling bias and influenced findings. In addition, therapists with different levels of experience and 
seniority participated in the focus groups, introducing a possible power differential within the group, and potential response bias. Finally, the perspectives of stroke survivors and health organisation managers were not included in this study; these viewpoints may have provided a more comprehensive analysis of the barriers and enablers of somatosensory rehabilitation.

\section{CONCLUSIONS}

This study used focus groups and interviews to explore the perspectives of occupational therapists and physiotherapists in the delivery of evidence-based somatosensory rehabilitation with stroke survivors and found individual, patient and organisational factors influence practice. Therapists experience barriers to change including a lack of knowledge and skills, lack of resources and organisational pressures. Facilitators for change were identified, including social support and therapists' perceived legitimacy in using new somatosensory rehabilitation approaches. The theoretical lens used in this study will guide implementation during the SENSe Implement study, a project aimed at increasing the use of an evidencebased sensory discrimination programme. ${ }^{16}$

\section{Author affiliations}

${ }^{1}$ Occupational Therapy, School of Allied Health, Human Services and Sport, La Trobe University, Melbourne, Victoria, Australia

${ }^{2}$ Neurorehabilitation and Recovery, Stroke, The Florey Institute of Neuroscience and Mental Health, Melbourne, Victoria, Australia

${ }^{3}$ Occupational Therapy, School of Allied Health, Australian Catholic University, Melbourne, Victoria, Australia

${ }^{4}$ Sydney School of Health Sciences, Faculty of Medicine and Health, The University of Sydney, Sydney, New South Wales, Australia

${ }^{5}$ The StrokeEd Collaboration, Sydney, New South Wales, Australia

${ }^{6}$ Occupational Therapy, Rural Department of Allied Health, Rural Health School, La Trobe University, Bendigo, Victoria, Australia

${ }^{7}$ Monash Department of Clinical Epidemiology, Cabrini Institute, Malvern, Victoria, Australia

${ }^{8}$ Department of Epidemiology and Preventive Medicine, School of Public Health and Preventive Medicine, Monash University, Melbourne, Victoria, Australia

${ }^{9}$ Department of Neuroscience, Central Clinical School, Monash University, Clayton, Victoria, Australia

${ }^{10}$ Allied Health (Occupational Therapy), Alfred Health, Melbourne, Victoria, Australia

Twitter Liana S Cahill @LianaCahill, Leeanne M Carey @LeeanneMCarey, Yvonne Mak-Yuen @YvonneMakYuen1, Annie McCluskey @Anniemccluskey2, Cheryl Neilson @CherylNeilson2 and Natasha A Lannin @NatashaLannin

Acknowledgements The authors acknowledge and thank the occupational therapists and physiotherapists who participated in this study.

Contributors LSC, LMC and NAL conceptualised the study. LMC was the research team lead. LSC and YM-Y conducted focus groups and individual interviews. LSC, LMC, NAL, DAO, CN and AM discussed and determined the approach to deductive analysis using implementation theory. LSC and AM were involved in thematic analysis. LSC, NAL and AM were involved in deductive analysis. LSC and NAL drafted the manuscript; all authors (LMC, DAO, YM- $Y, C N$ ) critically reviewed the manuscript and provided feedback.

Funding We acknowledge support for conduct of the research from the National Health and Medical Research Council (NHMRC) of Australia partnership grant: A network of sites and 'up-skilled' therapists to deliver best practice stroke rehabilitation of the upper limb (GNT 1134495) and NHMRC Ideas grant (GNT 2004443). LSC was supported by an Australian Government Research Training Programme Scholarship. NAL was supported by a Future Leader Fellowship
(102055) from the National Heart Foundation of Australia. DA0 is supported by a NHMRC Translating Research into Practice Fellowship (GNT 1168749).

Competing interests LMC is the lead author of the SENSe approach to sensory rehabilitation, the focus of knowledge translation in the SENSe Implement project. A SENSe training package (manual and DVD) has been developed and is available for purchase from a Not for Profit organisation. SENSe assessment and training equipment are also available for purchase. LMC has no personal financial interest in the sale of these resources. There is no patent, or intended application for a patent, associated with these resources. LMC has conducted workshops on the SENSe approach and been invited to give lectures and conference presentations on the approach.

Patient consent for publication Not required.

Ethics approval Ethical approval for this study was granted by the Austin Health Human Research Ethics Committee (Reference: H2013/04956 HREC/13/Austin/8) and La Trobe University (Reference FHEC 14/243). Site specific ethics approval was obtained for all participating sites.

Provenance and peer review Not commissioned; externally peer reviewed.

Data availability statement All data relevant to the study are included in the article or uploaded as supplementary information. Additional data relevant to the study are available upon reasonable request.

Supplemental material This content has been supplied by the author(s). It has not been vetted by BMJ Publishing Group Limited (BMJ) and may not have been peer-reviewed. Any opinions or recommendations discussed are solely those of the author(s) and are not endorsed by BMJ. BMJ disclaims all liability and responsibility arising from any reliance placed on the content. Where the content includes any translated material, BMJ does not warrant the accuracy and reliability of the translations (including but not limited to local regulations, clinical guidelines, terminology, drug names and drug dosages), and is not responsible for any error and/or omissions arising from translation and adaptation or otherwise.

Open access This is an open access article distributed in accordance with the Creative Commons Attribution Non Commercial (CC BY-NC 4.0) license, which permits others to distribute, remix, adapt, build upon this work non-commercially, and license their derivative works on different terms, provided the original work is properly cited, appropriate credit is given, any changes made indicated, and the use is non-commercial. See: http://creativecommons.org/licenses/by-nc/4.0/.

\section{ORCID iDs}

Liana S Cahill http://orcid.org/0000-0002-1730-9843

Leeanne M Carey https://orcid.org/0000-0001-6376-8613

Yvonne Mak-Yuen https://orcid.org/0000-0002-0476-1769

Annie McCluskey https://orcid.org/0000-0002-9719-6657

Cheryl Neilson https://orcid.org/0000-0002-0479-4149

Denise A 0'Connor https://orcid.org/0000-0002-6836-122X

Natasha A Lannin http://orcid.org/0000-0002-2066-8345

\section{REFERENCES}

1 Martinez-Arizala A. Methods to measure sensory function in humans versus animals. J Rehabil Res Dev 2003;40:35.

2 Carey LM, Matyas TA. Frequency of discriminative sensory loss in the hand after stroke in a rehabilitation setting. $J$ Rehabil Med 2011;43:257-63.

3 Connell LA, Lincoln NB, Radford KA. Somatosensory impairment after stroke: frequency of different deficits and their recovery. Clin Rehabil 2008;22:758-67.

4 Kessner SS, Schlemm E, Cheng B, et al. Somatosensory deficits after ischemic stroke. Stroke 2019;50:1116-23.

$5 \mathrm{Kim}$ JS, Choi-Kwon S. Discriminative sensory dysfunction after unilateral stroke. Stroke 1996;27:677-82.

6 Kalra L. Stroke rehabilitation 2009: old chestnuts and new insights. Stroke 2010;41:e88-90.

7 Sullivan JE, Hedman LD. Sensory dysfunction following stroke: incidence, significance, examination, and intervention. Top Stroke Rehabil 2008;15:200-17.

8 Pumpa LU, Cahill LS, Carey LM. Somatosensory assessment and treatment after stroke: an evidence-practice gap. Aust Occup Ther J 2015;62:93-104.

9 Stroke Foundation. National stroke audit: rehabilitation services report 2018. Stroke Foundation, 2018. https://informme.org.au/ stroke-data/Rehabilitation-audits [Accessed 20 June 2019] 
10 Winward CE, Halligan PW, Wade DT. Current practice and clinical relevance of somatosensory assessment after stroke. Clin Rehabil 1999;13:48-55.

11 Turville ML, Cahill LS, Matyas TA, et al. The effectiveness of somatosensory retraining for improving sensory function in the arm following stroke: a systematic review. Clin Rehabil 2019;33:834-46.

12 Carlsson H, Gard G, Brogårdh C. Upper-limb sensory impairments after stroke: self-reported experiences of daily life and rehabilitation. $J$ Rehabil Med 2018;50:45-51.

13 Connell LA, McMahon NE, Adams N. Stroke survivors' experiences of somatosensory impairment after stroke: an interpretative phenomenological analysis. Physiotherapy 2014;100:150-5.

14 Doyle SD, Bennett S, Dudgeon B. Upper limb post-stroke sensory impairments: the survivor's experience. Disabil Rehabil 2014;36:993-1000.

15 Doyle S, Bennett S, Fasoli SE, et al. Interventions for sensory impairment in the upper limb after stroke. Cochrane Database Syst Rev 2010;6:CD006331.

16 Carey L, Macdonell R, Matyas TA. Sense: study of the effectiveness of neurorehabilitation on sensation: a randomized controlled trial. Neurorehabil Neural Repair 2011;25:304-13.

17 Intercollegiate Stroke Working Party. Stroke guidelines. 5th ed, 2016. https://www.rcplondon.ac.uk/guidelines-policy/strokeguidelines

18 Stroke Foundation. Clinical guidelines for stroke management 2020 (living guidelines). Stroke Foundation, 2020. Available: https:// strokefoundation.org.au/What-we-do/Treatment-programs/Clinicalguidelines

19 Winstein CJ, Stein J, Arena R, et al. Guidelines for adult stroke rehabilitation and recovery: a guideline for healthcare professionals from the American Heart Association/American stroke association. Stroke 2016;47:e98-169.

20 Doyle SD, Bennett S, Dudgeon BJ. Sensory impairment after stroke: Exploring therapists' clinical decision making. Canadian Journal of Occupational Therapy 2014;81:215-25.

21 Bayley MT, Hurdowar A, Richards CL, et al. Barriers to implementation of stroke rehabilitation evidence: findings from a multi-site pilot project. Disabil Rehabil 2012;34:1633-8.

22 Doyle S, Bennett S, Gustafsson L. Clinical decision making when addressing upper limb post-stroke sensory impairments. British Journal of Occupational Therapy 2013;76:254-63.

23 Doyle SD, Bennett S. Feasibility and effect of a professional education workshop for occupational therapists' management of upper-limb poststroke sensory impairment. Am J Occup Ther 2014;68:e74-83.

24 Bauer MS, Damschroder L, Hagedorn H, et al. An introduction to implementation science for the non-specialist. BMC Psychol 2015;3:32.

25 Nilsen P. Making sense of implementation theories, models and frameworks. Implement Sci 2015;10:53.

26 Improved Clinical Effectiveness through Behavioural Research Group (ICEBeRG). Designing theoretically-informed implementation interventions. Implement Sci 2006;1:4.

27 Kislov R, Pope C, Martin GP, et al. Harnessing the power of theorising in implementation science. Implement Sci 2019;14:103.

28 Cane J, O'Connor D, Michie S. Validation of the theoretical domains framework for use in behaviour change and implementation research. Implement Sci 2012;7:37.

29 May C, Finch T. Implementing, embedding, and integrating practices: an outline of normalization process theory. Sociology 2009;43:535-54.
30 McEvoy R, Ballini L, Maltoni S, et al. A qualitative systematic review of studies using the normalization process theory to research implementation processes. Implement Sci 2014;9:2.

31 Atkins L, Francis J, Islam R, et al. A guide to using the theoretica domains framework of behaviour change to investigate implementation problems. Implement Sci 2017;12:77.

32 Cahill LS, Lannin NA, Mak-Yuen YYK, et al. Changing practice in the assessment and treatment of somatosensory loss in stroke survivors: protocol for a knowledge translation study. BMC Health Serv Res 2018;18:34

33 Hamilton AB, Finley EP. Qualitative methods in implementation research: an introduction. Psychiatry Res 2019;280:112516.

34 Braun V, Clarke V. Using thematic analysis in psychology. Qual Res Psychol 2006;3:77-101.

35 Terry G, Hayfield N, Clarke V. Thematic analysis. In: The SAGE Handbook of qualitative research in psychology, 2017: 17-37.

36 Macfarlane A, O'Reilly-de Brún M. Using a theory-driven conceptual framework in qualitative health research. Qual Health Res 2012;22:607-18

37 May C, Finch T, Rapley T. Normalisation Process Theory. In: Nilsen SBP, ed. International Handbook of implementation science. London: Edward Elgar, 2020.

38 McNaughton RJ, Steven A, Shucksmith J. Using normalization process theory as a practical tool across the life course of a qualitative research project. Qual Health Res 2020;30:217-27.

39 Sandström B, Willman A, Svensson B, et al. Perceptions of nationa guidelines and their (non) implementation in mental healthcare: a deductive and inductive content analysis. Implement Sci 2015;10:43.

40 Doyle S, Bennett S, Gustafsson L. Occupational therapy for upper limb post-stroke sensory impairments: a survey. British Journal of Occupational Therapy 2013;76:434-42.

41 McCluskey A, Vratsistas-Curto A, Schurr K. Barriers and enablers to implementing multiple stroke guideline recommendations: a qualitative study. BMC Health Serv Res 2013;13:323.

42 Meyer S, Karttunen AH, Thijs V, et al. How do somatosensory deficits in the arm and hand relate to upper limb impairment, activity, and participation problems after stroke? A systematic review. Phys Ther 2014;94:1220-31.

43 Carey LM, Lamp G, Turville M. The state-of-the-science on somatosensory function and its impact on daily life in adults and older adults, and following stroke: a scoping review. OTJR 2016;36:27S-41.

44 Michie S, Atkins L, West R. The behaviour change wheel: a guide to designing interventions. 2014. Great Britain: Silverback Publishing, 2015.

45 Jolliffe L, Hoffmann T, Lannin NA. Increasing the uptake of stroke upper limb guideline recommendations with occupational therapists and physiotherapists. A qualitative study using the theoretical domains framework. Aust Occup Ther J 2019;66:603-16.

46 Nelson MLA, Hanna E, Hall S, et al. What makes stroke rehabilitation patients complex? clinician perspectives and the role of discharge pressure. J Comorb 2016;6:35-41.

47 Currie K, King C, McAloney-Kocaman K, et al. Barriers and enablers to meticillin-resistant Staphylococcus aureus admission screening in hospitals: a mixed-methods study. J Hosp Infect 2019;101:100-8.

48 Al Shemeili S, Klein S, Strath A, et al. An exploration of health professionals' experiences of medicines management in elderly, hospitalised patients in Abu Dhabi. Int J Clin Pharm 2016;38:107-18.

49 Birken SA, Powell BJ, Presseau J, et al. Combined use of the consolidated framework for implementation research (CFIR) and the theoretical domains framework (TDF): a systematic review. Implement Sci 2017;12:2. 